\title{
Instructional quality of Massive Open Online Courses (MOOCs)
}

\author{
Anoush Margaryan*, Manuela Bianco, Allison Littlejohn \\ Caledonian Academy, Glasgow Caledonian University, Glasgow G4 OBA, UK
}

\section{A R T I C L E I N F O}

\section{Article history:}

Received 7 February 2014

Received in revised form

8 August 2014

Accepted 12 August 2014

Available online 26 August 2014

\section{Keywords:}

Massive Online Open Courses

Distributed learning environments

Evaluation methodologies

Lifelong learning

Pedagogical issues

\begin{abstract}
A B S T R A C T
We present an analysis of instructional design quality of 76 randomly selected Massive Open Online Courses (MOOCs). The quality of MOOCs was determined from first principles of instruction, using a course survey instrument. Two types of MOOCs (xMOOCs and cMOOCs) were analysed and their instructional design quality was assessed and compared. We found that the majority of MOOCs scored poorly on most instructional design principles. However, most MOOCs scored highly on organisation and presentation of course material. The results indicate that although most MOOCs are well-packaged, their instructional design quality is low. We outline implications for practice and ideas for future research.

(c) 2014 Elsevier Ltd. All rights reserved.
\end{abstract}

\section{Introduction}

Massive Open Online Courses (MOOCs) are said to be a new form of online learning.

The term was first used to describe an online open course 'Connectivism and Connective Knowledge (CCK08)', which was developed at the University of Manitoba by George Siemens and Stephen Downes and had over 2200 participants from all over the world. The course was conceived as an instantiation of the 'connectivist' approach to learning, whereby learning is perceived to take place through making connections to knowledge resources and people in the network (Siemens, 2005). Early MOOCs tended to have a decentralised, networkbased, non-linear structure focused on exploration and conversation rather than emphasising instructor-provided content. These constructivist MOOCs were termed 'cMOOCs' (Mackness, 2013).

cMOOCs remained relatively unknown until 2011 when a number of the leading Universities in the United States began to offer MOOCs via commercial platforms such as Coursera and Udacity (Milligan, Littlejohn, \& Margaryan, 2013). Unlike the original connectivist MOOCs, these MOOCs were hyper-centralised, content-based, and linear. They typically focused around a set of short, modularised video-lectures, followed by automated, multiple-choice testing of learners' understanding of the content. These MOOCs were termed 'xMOOCs'.

Since 2012, a growing number of universities have offered MOOCs worldwide and the public and academic discourse around MOOCs has intensified. MOOCs have been endorsed as a major advancement of higher education. For example 'Quality Matters', a US quality benchmarking and certification programme, argue MOOCs offer quality because they are designed for the 'typical student' and integrate with established higher education programmes (Legon, 2013). However, critics voiced concerns about the lack of novelty in the MOOC proposition and the exaggerated predictions of the scale of their impact on education and learning (Daniel, 2012; Gaebel, 2013). Specific concerns focus on the emphasis on access to 'high quality content' rather than paying attention to instructional design and the overall learning experience (OBHE, 2013). It has been suggested that MOOCs could provide public indices of quality that may expose weaknesses in teaching and learning in elite institutions (Daniel, 2012). However, there is no recognised system for quality measurement and even the metrics for measuring are under debate (OBHE, 2013).

Millions of people are learning in hundreds of MOOCs offered by universities and other public and private organisations worldwide. Yet there is very little empirical research into MOOCs and their effectiveness for learning (Liyanagunawardena, Adams, \& Williams, 2013; OBHE, 2013). Specifically, there has been no systematic analysis of the quality of instruction in MOOCs. There is emergent research on scoping key

\footnotetext{
* Corresponding author.

E-mail addresses: anoush.margaryan@gcu.ac.uk (A. Margaryan), Manuela.Bianco@gcu.ac.uk (M. Bianco).
} 
characteristics of MOOCs (Conole, n.d.; Weller, 2013), however, this work is focused on developing typologies of MOOCs rather than on the analysis of their instructional quality. As more and more universities invest (public) resources in setting up MOOCs, the consequent increase of both worldwide participation in them and media hype means that the question of whether or not MOOCs provide good quality instruction becomes pressing.

There are numerous ways to measure the quality of a course. Conventionally, course evaluations are based on course participants' and other key stakeholders' opinions of the quality of the course. While some studies examine learners' experiences of MOOCs (for example Fini, 2009; Kop, 2011; Kop \& Fournier, 2010; Kop, Fournier, \& Mak, 2011; Mackness, Mak, \& Williams, 2010; Milligan et al., 2013), these analyses tend to focus on learners' practices of learning and do not survey the instructional design quality of the courses.

While learners' and other stakeholders' experiences are important, the instructional design quality of a course is a critical indicator and prerequisite of the potential of the course for effective learning. Instructional design is a key component of the overall quality and pedagogic effectiveness of a learning experience. Yet most course evaluations do not take account of key principles of instructional systems design in the assessment of course quality. This is largely because, as explained earlier, evaluations are based on learners' opinions about the quality of courses, even though learners typically do not have the expertise to assess instructional design. Therefore it is critical to evaluate the quality of MOOC design by drawing on the knowledge of expert instructional designers. At present there are no published studies of instructional design quality of MOOCs.

This paper addresses this gap, by examining the instructional design quality of a sample of MOOCs (76 courses in total). The quality of these MOOCs is analysed from first principles and from the perspective of instructional design experts. The study aims to identify whether or not and to what extent the design of these MOOCs reflects these fundamental principles of instruction. This approach is original and unique within the current literature and discourse on MOOCs and the study contributes to the critical systematic analysis and evidence required to inform both public and academic debate and future development in the emergent domain of Massive Open Online Courses.

In the paper, we initially outline the key principles of instruction that formed the basis of the analysis. Second, we describe the methodology of the study and a 'Course Scan' instrument (based on the key principles of instruction) that we used to assess the instructional design quality of the MOOCs. Third, we present and discuss the findings of the study. Finally, we outline conclusions and some ideas for future research.

\section{Principles of instruction}

We assessed the instructional design quality of MOOCs using a set of key criteria based upon First Principles of Instruction - interrelated prescriptive criteria for effective instruction abstracted from key instructional design theories and models (Merrill, 2002, 2009, 2013). The five First Principles of Instruction are summarised below (for a comprehensive explanation of these principles and the underpinning learning theories see Merrill, 2013).

1. Problem-centred: Learning is promoted when learners acquire skill in the context of real-world problems. Many contemporary learning theories and instructional models - Constructivism, Authentic Learning, Cognitive Apprenticeship, Situated Learning, Problem-based Learning, Expansive Learning, to name a few - are premised on the idea that humans learn better when they are engaged in solving problems and building knowledge than when they are presented with information they are required to memorise. Merrill uses the term 'problem' to denote 'a wide range of activities, with the most critical characteristic being that the activity is some whole task rather than only components of a task and that the task is representative of those the learner will encounter in the world following instruction' (Merrill, 2002, p. 45). He contrasts problem-based instruction with topic-centred instruction where a subject is taught in isolation from the real-world tasks. Instructional effectiveness of a course will be enhanced if the learning activities in the course give learners an opportunity to solve real-world problems, working through a progression of interrelated tasks, from the least difficult to the most difficult, that reflect the complexity of real-world settings.

2. Activation: Learning is promoted when learners activate existing knowledge and skill as a foundation for new skill. This principle is rooted in a key tenet of instruction - to start where the learner is. Instructional effectiveness of a course will increase if the course includes learning activities that help learners to recall and describe their relevant previous experiences, and to relate and apply these to what they will learn in the course. If learners have not had relevant experience, then a course should begin by helping learners acquire such experience, for example by providing real-world or simulated examples that learners can use as a foundation for their new learning. However, activation requires more than enabling learners to recall or build relevant experience; activation also requires learning activities that stimulate the development of the mental models and schemes that can help learners to incorporate the new knowledge or skill into their existing knowledge.

3. Demonstration: Learning is promoted when learners observe a demonstration of the skill to be learned. This principle highlights the importance of showing learners what they could do to apply the new information or skill in new situations rather than merely presenting them information about what to do. Effectiveness of a course is enhanced, firstly, when learners are shown examples of both poor and good practices; secondly, when the demonstration is consistent with the type of knowledge or skill being taught; and, thirdly, when learners are guided to relate general information or an organising structure to specific instances of the knowledge or skill being taught.

4. Application: Learning is promoted when learners apply their newly acquired skill to solve problems. Merrill's review highlighted the almost universal agreement among contemporary learning theories that applying new knowledge or skill to real-world tasks is a necessary condition for effective learning. Merrill observes, however, that in many courses, application does not move much beyond requiring learners to answer multiple-choice questions about the material they are presented with. This principle emphasises that applying knowledge to a single problem is insufficient for learning and that a course must provide multiple opportunities for learners to apply their new knowledge or skill to a wide range of real-world problems. A key corollary to the application principle is appropriate learner guidance, through diminishing coaching or 'scaffolding'. The basis to this corollary is the observation shared by many learning theories that while in the early stages learners may need considerable support, as learners progress this support should be gradually 
taken away, with more control shifted to the learner to help build their independence. A key mechanism of scaffolding is feedback and most learning theories have long recognised feedback as the most important form of learner guidance.

5. Integration: Learning is promoted when learners reflect on, discuss, and defend their newly acquired skill. Learners have integrated new knowledge and skill into their everyday life when they are able to demonstrate change in behaviour or modification of their existing mental models and, when challenged, are able to defend their new knowledge or skill. Therefore, effectiveness of a course is enhanced when, firstly, learners are provided with opportunities to reflect on what they have learned in order to revise, synthesise, recombine and modify their new knowledge or skills; and, secondly, when learners are required to demonstrate and defend their new knowledge or skill to peers and others.

Merrill's meta-review $(2002,2013)$ indicated that these fundamental principles underpin all contemporary instructional design models and theories. A systematic review of 22 contemporary instructional theories confirmed theoretical support for these principles (Gardner, 2011a). Merrill (2002) highlights four points about the first principles. First, these principles are "relationships that are always taken to be true under appropriate conditions, regardless of programme or practice" (Merrill, 2002, p. 43). Second, they "can be implemented in any delivery system or using any instructional architecture" (Merrill, 2002, p. 44). Third, "learning from a given program will be promoted in direct proportion to its implementation of these principles" (Merrill, 2002, p. 44). Fourth, the principles are "design-oriented and prescriptive, rather than learning-oriented or descriptive - they relate to creating learning environments and products rather than describing how learners acquire knowledge and skills" (Merrill, 2002, p. 44).

Merrill's First Principles of Instruction focus on learning activities. These principles are augmented by a set of five further principles focused on learning resources (course materials or other people learners draw on to carry out the learning activities), and learning supports (the processes and procedures - such as expert feedback - that assist learners in carrying out learning activities). These additional principles were abstracted from the literature (Margaryan, 2008; Margaryan \& Collis, 2005) and include:

6. Collective knowledge: Learning is promoted when learners contribute to the collective knowledge.

7. Collaboration: Learning is promoted when learners collaborate with others.

8. Differentiation: Learning is promoted when different learners are provided with different avenues of learning, according to their need.

9. Authentic resources: Learning is promoted when learning resources are drawn from real-world settings.

10. Feedback: Learning is promoted when learners are given expert feedback on their performance.

This ten-principle framework was applied and tested for evaluation of instructional design quality of over one hundred online courses in a corporate university (Margaryan, 2008). A data collection instrument termed Course Scan was devised to measure the course design quality in relation to each of the ten principles (Margaryan, 2008; Margaryan \& Collis, 2005).

In this study we used a refined and extended version of the Course Scan instrument developed by Margaryan and Collis (2005). The following amendments were made to the instrument. First, items that are applicable only in a corporate learning context - such as relevance of activities and objectives to business needs and the involvement of learners' line managers - were removed. Second, some principles were operationalised in finer detail to enable a more nuanced analysis of the courses. For instance, additional items were added to the Course Scan to operationalise the principle of collective learning. The overall methodology of the study and the Course Scan instrument are described in the next section.

\section{Methodology}

\subsection{Data collection procedure and instrument}

Data was collected in October-December 2013. A researcher carried out an in-depth examination of the course environment of each of the 76 MOOCs in the sample, closely studying the course description, materials and resources, learning activity descriptions, learners' submissions and discussions in the course fora. Thus, all course-related information that could be accessed from the course website was examined in detail.

Subsequently, the researcher assessed the instructional design quality of each course using the Course Scan questionnaire. The questionnaire is based on two published instruments: Course Scan (Margaryan \& Collis, 2005) and The Expanded Pebble-in-the-Pond Instructional Design Checklist (Merrill, 2013). The full Course Scan instrument is enclosed in Appendix A. The Course Scan has three sections: 1) Course Details (7 items); 2) Objectives and Organisation (6 items); and 3) First Principles (24 items). Section 1 comprises openended questions about the course (such as course title, course dates, name of course instructor), while Sections 2 and 3 draw on a mixture or dichotomous (Yes/No) and four-point Likert-scale items (None-0; To some extent-1; To large extent-2; To very large extent-3) indicating evidence of the principles. Where relevant, 'Not applicable' and 'No information' options are provided. In the Course Scan (Appendix A), the 24 questions in Section 3, First Principles, map on the principles of instruction as follows: problem-centred (questions 3.1-3.5 and 3.9); activation (3.10); demonstration (3.6-3.7); application (3.11); integration (3.12); collective knowledge (3.14-3.16); collaboration (3.17-3.20, 3.23-3.24); differentiation (3.13); authentic resources (3.8); feedback (3.21-3.22).

The analysis involved a researcher surveying the course description, course materials and resources, learning activity descriptions, learners' submissions and discussions in the course website to determine if evidence for each of the items of the Course Scan (i.e. for first principles of instruction) could be found in each course and to what extent a particular principle was reflected in the course. The Likert-scale items were defined as follows:

- None - the course does not reflect a given principle or component at all.

- To some extent - there are serious omissions or problems; the principle is reflected in fewer than $50 \%$ of items (e.g. learning activities or objectives) being assessed. 
- To large extent - generally satisfactory, but there are some omissions or problems; the principle is reflected in between $51 \%$ and $80 \%$ of items being assessed.

- To very large extent - excellent; the principle is reflected in between $81 \%$ and $100 \%$ of items being assessed.

- Not applicable (N/A) - used when an item is missing. For example, when a course does not have group work activities or doesn't specify objectives, then N/A is selected for all those questionnaire items that relate to group work or objectives.

- No information - there is no information on the course website to enable an analyst to determine whether or not the course reflects a certain principle.

The survey and analysis of all course-related information and subsequent completion of Course Scan took an average of three hours for each course. The assessment of XMOOCs took (on average) less time than the assessment of cMOOCs. This is because xMOOCs, especially those provided via the same platform, are typically centralised and standardised in their design, while cMOOCs are much more dispersed and tend to have a more complex structure than xMOOCs do.

To ensure reliability and consistency in scoring, four courses (two cMOOCs and two xMOOCs) were examined by two researchers, who subsequently discussed the results in detail, comparing and contrasting each others' scorings until they agreed on scoring for each item. For this sub-sample of four courses, the inter-rater agreement was 80\% (representing agreement on 96 items out of 120 opportunities for agreement multiplied by 100). While the remaining courses were analysed and rated by the main researcher only, the two researchers met regularly (biweekly or more frequently) throughout the project to critically review and discuss the courses and their scores. At the end of the data collection phase, three detailed rounds of review of the whole dataset (Course Scan results of all 76 courses) were conducted. During this review the principal researcher explained and justified the scores to the other researcher to ensure both were satisfied with the consistency and accuracy of scoring.

This method of analysis of course design quality relies heavily upon the analysts' expertise in instructional systems design. Both researchers are experts in instructional design, having completed postgraduate degrees in instructional design supplemented by 12 years experience of instructional design across diverse sectors including corporate learning, higher education and an educational charity. One of the researchers had designed and applied an earlier version of the Course Scan to analyse over 100 online courses (Margaryan, 2008 ; Margaryan \& Collis, 2005).

\subsection{Sampling strategy and analysis}

First, a scoping of existent MOOCs was carried out using search engines and referrals from relevant blogs. There were two key criteria for inclusion of MOOCs in the study. First, courses had to be held in English, the shared language of both researchers. Second, the course websites had to be openly available within the timeframe of our project, between September and December 2013. The outcome of this scoping exercise was a list comprising 344 MOOCs: 318 xMOOCs and 26 cMOOCs.

Second, from this list of 344 courses, 76 courses (50 xMOOCs and 26 cMOOCs) were selected for analysis. As there were significantly fewer cMOOCs than XMOOCs, we examined the entire population rather than a sample of cMOOCs. Fifty xMOOCs were selected randomly from the list of 318 courses. The courses were selected by choosing 50 unique random integers between 1 and 150 and then marking the corresponding courses from a fixed list. Due to rapid changes in MOOC offerings, by the time data collection commenced eight courses were no longer available. In four cases the enrolment was closed, so the analyst could not register to access the course environment. In three instances, close examination of the courses revealed that they were not MOOCs, but Open CourseWare (OCW) or course units from an Open University. Finally, in one case the start date of the course was delayed to January 2014. Therefore, these eight courses were substituted with other courses in the sample. To maintain the proportions in terms of MOOC providers represented in the study, we randomly chose three substitute courses from Coursera, one from FutureLearn, two from Udacity, and two from Google. The full list of courses in the final sample is provided in Appendix B.

Given the labour-intensive nature of data collection and the limited number of analysts, our original intention was to limit the sample to 100 courses, selecting an equal number of xMOOCs and cMOOCs, 50/50. However, as explained earlier, the scoping phase of the study revealed that there were significantly fewer cMOOCs than xMOOCs. Only 26 cMOOCs fitted the selection criteria. Therefore, we had to reduce the number of cMOOCs in the study. We purposefully selected an uneven number of xMOOCs and cMOOCs - 50 xMOOCs and 26 cMOOCs - rather than reducing the overall sample size by reducing the number of xMOOCs to 26, in proportion to cMOOCs.

Raw data were captured in an Excel spreadsheet. Subsequently, the data were transferred to SPSS, where they were coded and analysed using descriptive statistical tests.

\section{Findings and discussion}

The majority of MOOCs, both XMOOCs and cMOOCs, attained a low score on the majority of the principles (Table C.1). For each course, the range of possible scores was $0-72$, with 0 indicating that none of the principles and organisational criteria was reflected in the course, and 72 indicating that all principles and criteria were reflected to a very high standard. We found that for the overall sample of 76 MOOCs, the range of scores was $0-28$ points (median 9; mode 6; StD 5.93). For xMOOCs, the range was 3-25 points (median 8; mode 6; StD 4.46); and for cMOOCs the range was 0-28 (median 11; mode 9; StD 7.24). Detailed findings are outlined in Tables C.1-C.5 in Appendix C. Results are summarised and discussed below.

To what extent are MOOCs problem-centred? We examined the extent to which course objectives were relevant to real-world problems; problems and activities in the course were typical of those learners encountered in the real world; and problems were divergent and ill-structured rather than having one correct solution. The majority of MOOCs in our sample (67/76) were not problem-centred (Table C.3). Only 8/76 courses (4 cMOOCs (8\%) and 4 xMOOCs (15\%)) included learning activities based around authentic, ill-structured and divergent problems typical of those that are encountered in the 'real world' (Tables C.4 and C.5).

To what extent do MOOCs enable activation of existing experience? In 68/76 courses, learning activities did not require learners to relate the course material to their prior knowledge and skills (Table C.3). Only in 7/76 courses (1 xMOOC and 6 cMOOCs) had learning 
activities that tried to activate prior knowledge or skills (Tables C.4 and C.5). For example, in a course on entrepreneurship, the instructor began by presenting a series of 'real-world' examples of start-ups, encouraging participants to reflect on their own understanding of and experience with start-ups and relating these to the course material. Similarly, in a course on physics, learning activities required participants to carry out real-life experiments or reflect on everyday situations in order to develop their own explanation of certain physical phenomena, before learning the concepts and formulae that describe these physical phenomena.

To what extent do MOOCs reflect the principle of demonstration? The principle of demonstration was operationalised as the availability of examples of problem solutions and the extent to which these represent a range of quality from excellent to poor solutions. As described earlier, the majority of courses in our sample were not problem-centred (Table C.3). Of the 8 problem-centred courses, only 3 courses, of which two xMOOCs and one cMOOC, had examples of problem solutions. In only one of these, a cMOOC, there were both good and bad examples provided (Tables C.4-C.5).

Do MOOCs enable learners to apply their new knowledge or skill to solve problems? In $45 / 76$ courses (68\% of xMOOCs and $42 \%$ of cMOOCs), none of the learning activities focused on application (Table C.3). In 18/76 (20\% of xMOOCs and 31\% of cMOOCs), learning activities reflected the principle of application to some extent; in 8/76 courses (6\% of xMOOCs and $19 \%$ of cMOOCs) to large extent; and in $5 / 76$ of courses (6\% of xMOOCs and $8 \%$ of cMOOCs) to very large extent (Tables C.4-C.5). For example, in one course, participants learned by designing prototypes of artifacts, as well as studying the design process in theory. In another course, participants learned about business strategy by conducting competitor analysis or analysing capabilities of real-world companies.

To what extent do MOOCs encourage learners to integrate new knowledge or skill? There was limited evidence of the integration principle within the MOOCs we surveyed (Table C.3). We found evidence of learning activities focused on integration in only 5/76 courses, one xMOOC and four cMOOCs (Tables C.4-C.5).

Do MOOCs encourage learners to contribute to collective knowledge? The principle of collective knowledge was operationalised as the extent to which the learning activities required participants to learn from each other; contribute to rather than merely consume collective knowledge; and build on other participants' work. While in the majority of MOOCs we surveyed (49/76, including 48\% of xMOOCs and $96.2 \%$ of cMOOCs) learning activities required participants to learn from each other, only $16 / 76$ courses (10\% of xMOOCs and $42.2 \%$ of cMOOCs) required learners to contribute to collective knowledge. In the majority of courses (75/76), learning activities did not require participants to build on others' work. The only course in which they did build on others' work (to some extent) was a cMOOC (Tables C.4-C.5).

Do MOOCs enable collaborative learning? The principle of collaboration was operationalised as the extent to which learning activities required participants to collaborate with other course participants and others outside the course, the diversity of these peer-interaction groups and the extent to which individual contributions of each learner in a group could be clearly identified. There were no collaborative activities in 68/76 MOOCs (Table C.3). Only in one xMOOC and seven cMOOCs (29.6\% of all surveyed cMOOCs) a limited number of learning activities required participants to collaborate with each other (Tables C.4-C.5). Of these, only two courses (both xMOOCs) required learners to collaborate with others outside the course (Table C.4). Finally, out of the eight MOOCs, which had some collaborative activities, none required the peer groups to be diverse. In most cases, learners were given no direction about the composition of the group and in one case learners were specifically encouraged to form a group with others like them. Finally, none of these eight collaborative MOOCs had measures in place to make sure that individual contributions of each learner in a group could be clearly identified (Table C.3).

Are MOOCs supportive of learners with different learning needs? The principle of differentiation was operationalised as the extent to which MOOCs provided learning activity options for participants with various learning needs. The majority of courses surveyed had the same set activities for all participants. Only 21/76 courses had activity options (Table C.3). These included three xMOOCs (6\% of all xMOOCs) and 16 cMOOCs (61.5\% of all cMOOCs) in which the principle of differentiation was reflected to a limited extent, and a further 2 cMOOCs (7.7\%) where the principle was reflected to a large extent (Tables C.4-C.5). MOOCs that reflected the principle of differentiation provided three types of options: options for learning activities, options for learning resources, and options for media/technologies. For example, in one course participants were given a range of learning activities and could choose which activities they wanted to carry out, depending on their own individual learning path based on their goals and needs. In another course, participants were offered a broad range of resources that they could use to complete an activity and given the option of selecting the resources on the basis of their own goals and needs. Finally, some courses allowed participants to submit their assignments using media and technologies of their own choice (blog and/or Twitter; video and/ or audio and/or text).

Are the learning resources in MOOCs authentic? Only slightly over a third of the MOOCs we analysed (27/76) had authentic resources (Table C.3). These included 13 xMOOCs (26\% of all xMOOCs surveyed) and 14 cMOOCs (53.8\% of all cMOOCs in the sample) (Tables C.4-C.5).

Do MOOCs provide expert feedback to learners? We examined whether or not courses included feedback by course instructors on the learning activities and assignments, and if the process and criteria of feedback were clearly explained to the participants. None of the MOOCs we surveyed had instructor feedback (Table C.3). Only expert instructor feedback on learning activity results (assignments, tasks or problem solutions) was taken into consideration. We did not consider peer feedback or machine 'feedback' such as from an assessment quiz as 'expert feedback'. In some cMOOCs, instructors and participants were part of an ongoing interaction, for instance through discussion fora. Analysis of these discussion fora showed that interactions were general and non-specific rather than providing in-depth, targeted expert feedback on a learner's performance on specific learning activities and tasks. Therefore these forms of learner-instructor interaction were not considered evidence of feedback.

In addition to the ten instructional principles underlying the design of learning activities, learning resources and learning supports, the Course Scan included a set of key criteria for assessing the quality of organisation and presentation of a course. Four organisational criteria were included. First, we examined whether or not courses specified learning objectives and determined the extent to which course objectives were measurable. Second, we analysed whether or not the course had specified learning outcomes (defined as the change in the skill set of learners, that is, what the learners will be able to do upon completion of the course). Third, we investigated the extent to which course materials were well-organised (logically structured and easy to find). Fourth, we determined whether or not the course requirements and the overall course description were clearly articulated.

In many courses (22/50 xMOOCs and 17/26 cMOOCs), no learning objectives were specified (Table C.2). Where objectives were specified, these objectives were largely not measurable (Table C.2). Only in three xMOOCs (6\%) and four cMOOCs (15.3\%) were the objectives 
measurable (Tables C.4-C.5). Only one course in the whole sample - an xMOOC - scored the highest (3) points for measurability of objectives (Table C.4), while in 2/76 courses objectives were measurable to large extent, and in 4/76 courses they were measurable to some extent (Tables C.4-C.5). The majority of courses (61/76, 80.3\%) did not specify any learning outcomes (Table C.2). Learning outcomes were specified in only 10/50 (20\%) xMOOCs and 5/25 (19.2\%) cMOOCs (Tables C.4-C.5).

As to the organisation of course material, nearly all MOOCs of both types scored highly on this criterion: 49/50 xMOOCs and 22/26 cMOOCs. A significant proportion of courses scored the highest point (3) for this aspect of their design: $42 / 50$ (84\%) xMOOCs and $14 / 26$ (53.8\%) cMOOCs (Tables C.4-C. 5). Similarly, in the majority of MOOCs we surveyed, course requirements were clearly specified (55/76 courses, including 38/50 xMOOCs (76\%) and 17/26 cMOOCs (65.4\%)). Course descriptions were clearly stated in 65/76 courses, including 46/ 50 xMOOCs (92\%) and 19/26 cMOOCs (73.1\%) (Tables C.4-C.5).

These findings indicate that the instructional design quality of MOOCs is low. Some MOOCs implement some of the principles and occasionally implement these principles to a high standard. None of the MOOCs incorporate all the principles. However, nearly all MOOCs are 'well-packaged', comprising well-organised, clearly articulated and attractively presented course material.

In comparison to XMOOCs, more cMOOCs scored higher on the criteria of authenticity of learning activities and resources; measurability of learning objectives; activation of prior knowledge/skill; application and integration of new knowledge/skill; collaboration with and learning from other participants; contributing to collective knowledge; and accommodating learners' preferences. In contrast, xMOOCs slightly outperformed cMOOCs in terms of the organisation and presentation of course material. Compared to cMOOCs, xMOOCs were slightly better at including learning activities that require learners to broaden their range of collaboration by working with others outside the course rather than only teaming up with other course participants.

\section{Conclusions}

The study provides a critical, systematic analysis and evidence base of instructional quality of MOOCs. The analysis is based on a set of first principles of instruction, derived from the main contemporary learning and instructional theories and models. We analysed the quality of instructional design of 76 Massive Open Online Courses (MOOCs), including 50 content-based xMOOCs and 26 connectivist cMOOCs. We found limited evidence of first principles of instruction in these MOOCs. Most courses implemented only some of the principles, with the majority of MOOCs of both types scoring low on the extent to which these principles were implemented. None of the courses implemented all of the principles. Out of 72 possible total points that each course could score according to the Course Scan instrument, none of these MOOCs scored above 28 points. The range of scores was: for xMOOCs 3-25 points; for cMOOCs $0-28$ points. The findings indicate that instructional design quality of MOOCs is essentially low.

As MOOCs proliferate, drawing in increasing numbers of faculty and learners worldwide, the issue of their instructional quality becomes increasingly pressing. This study highlights a number of key areas in which instructional design of these courses should be improved. In massive online courses, implementing some of the principles, for example providing learners with high quality, expert human feedback, is a non-trivial task. Yet if academics and universities continue offering MOOCs, as they no doubt will, they must rethink the MOOC design model from the first principles. Many learners are drawn to MOOCs by the 'brand' of the universities and academics, expecting rigour and quality traditionally associated with these institutions. Yet what learners find in MOOCs may be a mirage of quality education.

While we can speculate about the reasons explaining the limited implementation of instructional design principles within MOOCs, we cannot offer evidence-based insights into the causes of the poor instructional quality of MOOCs. There is a range of potential causes. For instance, instructors and designers of the MOOCs may lack knowledge of the contemporary instructional design principles or learning theories. Or, perhaps they are well aware of the principles and practice these routinely in their classroom teaching but not in their MOOCs. Or, in offering these MOOCs, the instructors may be driven predominantly by their institutional marketing considerations rather than by pedagogic concerns. As we did not examine the background, motivations and goals of individuals and institutions who developed these MOOCs, we cannot say why the MOOCs have poor instructional designs. Future research could investigate institutions' and individual academics' and instructional designers' rationale, goals and motivations underpinning their involvement in MOOCs, examining the broader design and quality assurance processes and organisational contexts within which MOOCs are developed. Also, we cannot say whether our findings are a reflection on MOOCs only or whether similar deficiencies in instructional design quality would be uncovered in a random sample of other face-to-face or online, non-MOOC courses.

In recent years several studies applied the first principles of instruction to evaluate online and blended learning courses in a variety of contexts and domains (Collis, Margaryan, \& Amory, 2005; Frick, Chadha, Watson, \& Zlatkovska, 2010; Gardner, 2011b; Margaryan, 2008; Margaryan \& Collis, 2005). In the future, researchers could use these principles (and the Course Scan) to carry out systematic comparative studies of instructional quality of different types of courses. Furthermore, the ten-principle framework could be applied to analyse a larger sample of MOOCs from a broader range of platforms and countries. Future analysis could detail distinctive characteristics of MOOCs, which scored highly on some of the principles, identifying similarities and patterns in these characteristics. xMOOCs delivered through different commercial platforms could be compared to ascertain any significant differences and patterns in their designs. Finally, future studies could examine interrelationships between instructional design quality (as determined by Course Scan results) and other aspects of course quality, such as improved learning and learner satisfaction (as determined by other types of course evaluation).

The ten principles are fundamental criteria of instructional quality, therefore they can be applied to evaluate any form of structured instructional courses rather than only MOOCs and other types of online courses, including 'classroom-only' courses. However, the Course Scan methodology is devised to enable the application of the ten principles to evaluate primarily online courses. Applying the methodology to classroom-based or blended learning courses would require significant modifications to the procedure, as well as introduction of additional data collection instruments. For example, if researchers were to apply the methodology to classroom-only or blended learning courses, they would have to make provisions for collecting data about learning activities that occur physically in the classroom and that are not captured online, perhaps by combining classroom observation with the analysis of course materials, resources, and assignments. So when using the ten principles of instruction to analyse classroom-based or blended learning courses, a different evaluation methodology should be devised. 
The ten principles represent a synthesis of what we know from contemporary instructional theories about what constitutes effective instruction. Therefore, courses should strive to follow as many of these principles as possible. However, we acknowledge that in some courses implementing all these principles will not be a straightforward task, and that in some courses some of these principles may have to be more strongly emphasised than others. Merrill suggests that the successive application of the first principles of instruction defines increasingly effective levels of instructional strategy' (2013, p. 22). He proposes a hierarchy of importance of these principles, whereby the demonstration principle represents the first level of effectiveness; the application principle the second level of effectiveness; the problemcentred principle defines the third level, while including the activation and integration principles further increases the effectiveness of instruction (Merrill, 2013). However, a discussion of a hierarchy of importance of principles is beyond the scope of our paper. The purpose of this study was to ascertain the extent to which all principles have been reflected in our sample of MOOCs. Therefore, in reporting our findings, it is important to address the extent of implementation of each principle rather than applying the principles selectively.

This paper has important implications for practice. The framework proposed in this study could help faculty and instructors offering MOOCs to design better-quality learning. The principles could serve as an evaluation framework for quality control and improvement of the implementation of MOOCs. Existing evaluation frameworks focus on learners' opinions and experiences of learning, but tend to disregard instructional design quality, which is an important variable in the overall quality of a course. The ten principles and the Course Scan instrument presented in this paper can be used in conjunction with other evaluation methods (such as the evaluation of learners' experiences) to broaden the scope and the depth of assessment of the quality of MOOCs. The ten-principle framework and the Course Scan can be integrated into course production processes as a quality control mechanism (for examples and suggestions on how this can be achieved, see Margaryan, 2008). Even though MOOCs are still in the experimental phase, they would benefit from the application of instructional design principles.

\section{Appendix A. Supplementary data}

Supplementary data related to this article can be found at http://dx.doi.org/10.1016/j.compedu.2014.08.005.

\section{References}

Collis, B., Margaryan, A., \& Amory, M. (2005). Multiple perspectives on blended learning design. Journal of Learning Design, 1(1), 12-21.

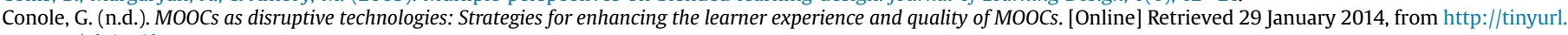
$\mathrm{com} / \mathrm{qb} 4 \mathrm{oz} 8 \mathrm{~h}$.

Daniel, J. (2012). Making sense of MOOCs: Musings in a maze of myth, paradox and possibility. Retrieved on 29 January 2014 , from http://jime.open.ac.uk/2012/18.

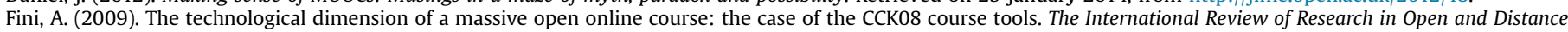
Learning, 10(5) [Online] http://www.irrodl.org/index.php/irrodl/article/view/643/1402.

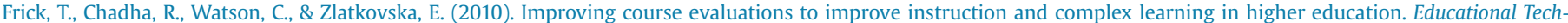
nology Research and Development, 58, 115-136.

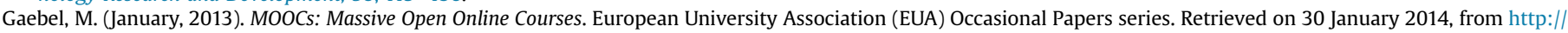
www.eua.be/Libraries/Publication/EUA_Occasional_papers_MOOCs.sflb.ashx.

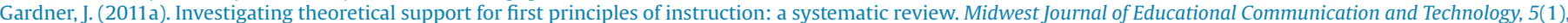
$8-17$.

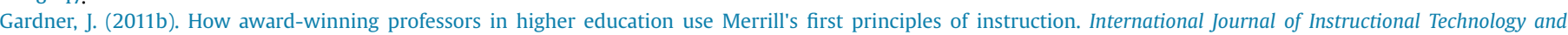
Distance Learning, 8(5), 3-16.

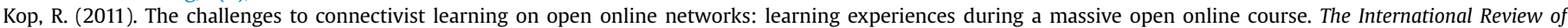
Research in Open and Distance Learning, 12(3), 19-38 [Online] http://www.irrodl.org/index.php/irrodl/article/view/882/1689.

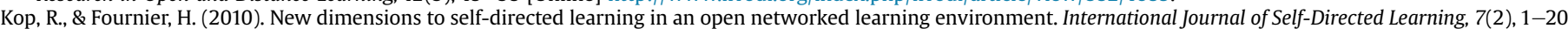
[Online] http://www.sdlglobal.com/IJSDL/IJSDL7.2-2010.pdf.

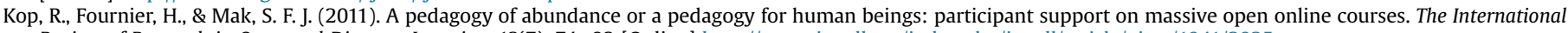
Review of Research in Open and Distance Learning, 12(7), 74-93 [Online] http://www.irrodl.org/index.php/irrodl/article/view/1041/2025.

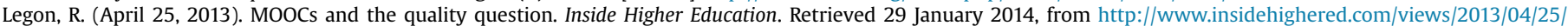
moocs-do-not-represent-best-online-learning-essay.

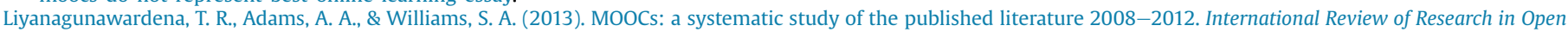
and Distance Learning, 14(3), 202-227.

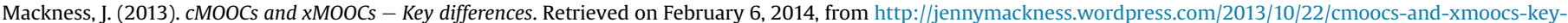
differences/.

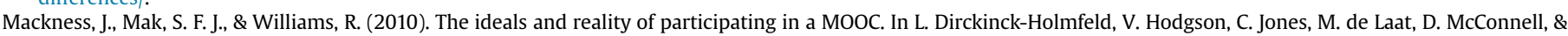
T. Ryberg (Eds.), Proceedings of the Seventh International Conference on Networked Learning (pp. 266-275). Lancaster, UK: University of Lancaster [Online] http://www. lancaster.ac.uk/fss/organisations/netlc/past/nlc2010/abstracts/PDFs/Mackness.pdf.

Margaryan, A. (2008). Work-based learning: A blend of pedagogy and technology. Saarbruecken: AV Akademikerverlag.

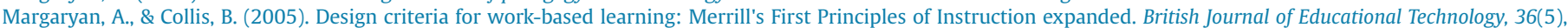
725-738.

Merrill, M. D. (2002). First principles of instruction. Educational Technology Research and Development, 50(3), 43-59.

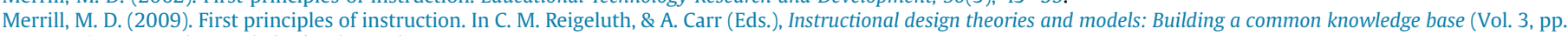
3-26). New York: Routledge/Taylor and Francis.

Merrill, M. D. (2013). First principles of instruction: Identifying and designing effective, efficient and engaging instruction. Hoboken, NJ: Pfeiffer/John Wiley \& Sons.

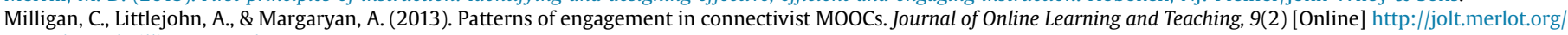
vol9no2/milligan_0613.htm.

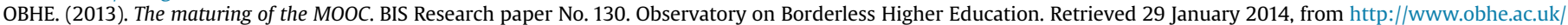
documents/download?id=933.

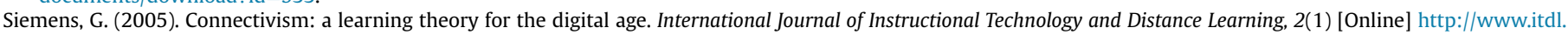
org/Journal/Jan_05/article01.htm.

Weller, M. (2013). The MOOC learning design project [Online] http://ld.h817open.net/ld1/. 